Research Article

\title{
How Did the COVID-19 Pandemic Affect Higher Education Learning Experience? An Empirical Investigation of Learners' Academic Performance at a University in a Developing Country
}

\author{
Ghada Refaat El Said \\ Department of Management Information Systems, Future University in Egypt (FUE), 90th Street, Fifth Settlement, \\ New Cairo, Egypt \\ Correspondence should be addressed to Ghada Refaat El Said; ghada.refaat@fue.edu.eg
}

Received 6 October 2020; Revised 4 January 2021; Accepted 24 January 2021; Published 10 February 2021

Academic Editor: Thomas Mandl

Copyright (c) 2021 Ghada Refaat El Said. This is an open access article distributed under the Creative Commons Attribution License, which permits unrestricted use, distribution, and reproduction in any medium, provided the original work is properly cited.

\begin{abstract}
COVID-19 has dramatically reshaped the way global education is delivered. Millions of learners were affected by educational institution closures due to the pandemic, which resulted in the largest online movement in the history of education. With this sudden shift away from classrooms in many parts of the globe, universities had to rapidly shift to virtual and digital strategies. Many believe that the adoption of online distance learning will persist after pandemic. A new hybrid model of education is expected to emerge, and, given the digital divide, new shifts in education approaches could widen equality gaps. This is one of the first empirical studies investigating the effect of the sudden shift from face-to-face to online distance learning due to COVID-19 lockdown at one of the universities in Egypt. Comparison of grades was made between 376 business students who completed a face-to-face course in spring 2019 and 372 students who completed the same course but fully online via distance learning mode in spring 2020 during the lockdown. T-test was conducted to compare grades of quizzes, course work, and final exam for the two groups. Chi-square test was used to compare grade distribution for both groups. The effect of gender, credit hours, age, and CGPA was assessed. The results suggested that there was no statistically significant difference in students' grades. In addition, the unplanned and rapid move to online distance learning at the time of pandemic did not result in a poor learning experience as was expected. The study also included a survey of 435 students and interviews with a sample of professors about their learning and teaching experience during the lockdown. The results of this study provide specific recommendations for universities, instructors, and higher education portal designers about future application of online distance learning. Since Egypt decided to make the shift to online distant learning in all future higher education plans, the results of this research would be especially vital for universities in Egypt and other developing countries. If administered correctly, this shift could lead to a larger learner population, more cost efficiencies, and more university revenue.
\end{abstract}

\section{Introduction}

In 2019 and even before COVID-19, there was already high growth and adoption in education technology, with global investments of US $\$ 18.66$ billion in 2019, estimated to reach $\$ 350$ billion by 2025 [1]. Learning management systems are now commonplace in higher education for both on-campus and distance students. In 2015, the annual growth rate of online enrolment was increasing with an extremely rapid rate of over $30 \%$ every year, and in 2019 , the number of students taking at least one online course has been grown to 34.7 percent of the total learner's population worldwide [2]. In early 2020, COVID19 has resulted in schools and universities being shut all across the world, making around 1.2 billion learners out of the classroom. This leads to a distinctive rise of distance learning, whereby teaching is undertaken remotely and on digital platforms [1]. According to Hodges [3], well-planned online learning is totally different from shifting online in response to a crisis, as the speed with which this shift is done could be shocking to faculty members and learners.

Until now, there have been few investigations into how universities all over the world have dealt with the COVID-19 
pandemic and how they are currently preparing for the coming semester [4]. However, such stocktaking is necessary, in order to support higher education institutions to overcome the lockdown, which is expected to continue in 2020 and 2021. Information on how other universities have behaved and a look at other countries and the universities there can be very helpful. A large number of analyses and forecasts have already been posted on the possible COVID-19 impact on higher education. QS, Educations.com, and Studyportals [5] are currently conducting three international surveys of university staff and students and prospective students on the COVID-19 impact on their study or mobility plans [2]. The results of these surveys are presented in the form of web talks and blogs. Very few empirical academic studies have been published about this phenomenon; literature dedicated to understanding how the online distance learning conducted during the COVID-19 lockdown has impacted academic practices in higher education is still under development. Furthermore, to date, little work is available comparing student performance in online distance learning during lockdown versus face-to-face courses in previous semesters.

The highest majority of prepandemic literature which compared face-to-face with online distance courses was conducted in higher educational institutions in developed countries, where information technology infrastructure, resources, and support are available and reliable. There is a severe shortage of similar comparative studies in developing countries, in which the poor IT infrastructure and lack of financial resources and technical support, as well as modest IT skills for instructors and students, are main challenges for online distance learning adoption $[6,7]$.

This study investigated the overall learning experience after the sudden shift from face-to-face to online distance learning due to the COVID-19 lockdown at one of the universities in Egypt. The study assessed variation in students' academic performance from Spring 2020 semester and the semester before and collected professors' feedback and students' satisfaction. This investigation will contribute to the current literature by providing a clear insight about the effect of the interruption of face-to-face education due to the pandemic. In addition, the recommendations provided based on the findings of the study may help rectify the situation and guide educational leaders, professors, and higher education portals designers for integrating online distant learning in future higher education plans of their institutions, especially in developing context, where lack of IT infrastructure and skills represents big challenges.

This paper begins by providing background on previous research on online distance learning and the COVID-19 lockdown in Section 2. This is followed by a description of the research methodology, procedures, and data collection in Section 3. Results and discussion are presented in Section 4 , followed by the recommendations in Section 5. Finally, the research conclusion, limitations, and suggestions for possible future work are included in Section 6.

\section{Literature Review}

2.1. Online Distance Learning versus Face-to-Face Comparative Studies. A large number of studies, before pandemic, compared face-to-face with online distance courses in terms of university student performance, as well as many other academic and demographic variables of students. For example, Soesmanto and Bonner [8] evaluated a dual mode design in which students of year one of a business school at the Griffith University in Australia have the option to undertake the same statistics course in a face-to-face mode and/ or an online mode. The comparative analysis suggested no significant differences in learning satisfaction and academic performance of the two cohorts within the dual mode system. In a similar study done in California State University, Tan [9] suggested that, with proper training and support of technology, university instructors are delivering both the on-ground and online sections of a business technology course with the same effectiveness as measured by students' grade points.

For a different type of courses, Lorenzo-Alvarez et al. [10] found that a radiology course taught online at a university in Australia resulted in similar academic outcomes to F2F learning. In their online vs. face-to-face comparative study, Cavanaugh and Jacquemin [11] compared gradebased learning outcomes between online and face-to-face course taught at Ohio University, using a large dataset of 5,000 courses taught by over 100 faculty members over a period of ten academic terms at a large, public, four-year university. Given the large scale of the study, the results suggest no difference in grade-based student performance between instructional modes for courses where both modes are applicable. According to the regression analysis of the study, the primary influence on individual course grades was student GPA. Students with higher GPAs performed better in online courses, and students with lower GPAs performed worse when taking courses in an online format compared to a face-to-face format.

Nyer [12] investigated effective ways of quickly offering an online lecture in a course that is otherwise taught using traditional face-to-face lectures at Chapman University in California. The study compared student learning outcomes (using test scores) across three modes of delivering lectures: (1) using a traditional face-to-face lecture, (2) using online instruction where the lecture was delivered using a video recording of the classroom lecture, and (3) using online instruction where the lecture was delivered using a static document created from an edited transcript of the classroom lecture embedded with charts, graphs, etc. The results showed that quickly created online instruction methods scored lower in engagement compared to the traditional face-to-face lecture. Students who were exposed to the online lecture delivered using a static document and students attending the face-to-face lecture both reported having higher quality of notes compared to students exposed to the video recording. Finally, the effect of the different instructional material on student test scores was found to be mediated by student engagement and perceived note quality.

2.2. Online Distance Learning and the COVID-19 Lockdown. The research of Bozkurt et al. [13] is one of the early studies reporting the impact of the interruption of education due to 
COVID-19 pandemic in 31 countries. In addition to the assessment of each case by country, the study highlighted major themes that have commonly arisen in these countries from the interruption of education during COVID-19, such as (1) the inequity and the digital divide which have been aggravated during the pandemic, (2) the need for alternative assessment and evaluation methods and the needed switch to formative assessments through both synchronous and asynchronous means, and (3) the use of online proctoring services as a way to control for cheating and academic dishonesty.

The research by Hjelsvold et al. [14] is also one of the first studies which investigated educators' feedback on the distance learning during the COVID-19 lockdown, as a result of a survey conducted on 303 university students and 56 educators in Norway. The study reported that short time and lack of ready resources were important barriers to sudden shift to distant learning. Even though learners and educators report a lack of practice in online education, the study declared that they both adapted fast, showing a positive attitude towards the change. According to the results of the survey, key factors affect the online experience during the first weeks of distance learning, and these are as follows: from learners' side: feedback to instructors, engagement in discussion forums, use of online tutorials, and participation in group work; from educators' side: timely communication and clear instructions about formative and summative assessments, exams, quizzes and assignments, informing learners of how to get help, providing support using synchronous and asynchronous tools, ensuring virtual place for students-to-students and students-to-instructor online interaction, and giving advice to students to set their study place and schedule for an effective study-at-home experience; from leaders and administrators' side: timely communication with students especially with exam regulations and petitions, supporting learners in preparing new pedagogical approaches to teaching as well as learning new tools, and providing a more collective approach to the coordination of activities and collaboration between educators.

\subsection{Online Distant Learning and Higher Education Plans in} Egypt after COVID-19. Egypt has the largest education system in the Middle East and North Africa region with 52,000 schools, accommodating 20 million school students, and 44 universities with 830 higher education institutions, accommodating 3 million higher education students [15]. In March 2020, the Egyptian government made a set of immediate precautionary decisions to confront the dangers of the emerging Corona virus, the most important of which was the closure of all schools, universities, and higher education institutions. The Egyptian Ministry of Higher Education and Scientific Research, to ensure the continuation of the educational process, urged higher education institutions to apply distance education as a modality during the lockdown [16].

In May 2020, four nation-wide surveys were administered to assess the Egyptian experience of distance education in Egyptian universities and higher institutes, to measure the satisfaction of educational leaders, professors, administrators, and students, and to set an integrated vision of the future of distance learning in higher education in Egypt. The data collection was based on the crowdsourcing approach, whereby surveys were placed on various portals. A total of 106,897 participants filled the survey: 1,041 educational leaders, 11,100 faculty members, 1,258 administrative staff, 89,867 Egyptian students, and 3,631 international students.

The results of the four surveys included the following: the majority of educational leaders endorsed online distant learning in higher education; Internet connectivity and weak IT skills are the most prominent difficulties of distance education in Egypt; and recorded lectures are the most plausible ways to deliver educational materials [16]. Based on the recommendations of these nation-wide surveys, the government of Egypt decided to integrate face-to-face with online distant learning in all future higher education plans. This plan for merging on-campus and online distant learning will not only put the Egyptian universities in a state of movement for any urgent conditions such as COVID-19, but most importantly achieve vital educational objectives, such as reducing student density, making the best use of the expertise of professors and technological infrastructure of universities, and making a gradual transformation of students to lifelong learners [16].

This study investigates the overall learning experience after the sudden shift from face-to-face to online distance learning due to COVID-19 lockdown at one of the universities in Egypt. Since Egypt decided to integrate online distant learning into all future higher education plans, the main aim of this study is to provide recommendations for future application of this mode of learning in the Egyptian higher education institutions. The main research question of the current study is to determine if there was a statistically significant difference in terms of academic performance between face-to-face learners of an undergraduate course taught on-campus in Spring 2019 and learners who completed the same course but fully online via long distance learning during the COVID-19 lockdown in spring 2020 semester. The study also assesses professors' feedback and students' satisfaction concerning the online distance learning experience during the lockdown.

\section{Methodology}

The sudden shift to online learning during the COVID-19 pandemic is suggested to be a social phenomenon [17] that involves culture, technology, and human behavior, where multiple perspectives must be taken into account [18]. Hence, the use of multiple research methods and the use of a multiplicity of techniques are essential. Having said that, both descriptive and quantified description of the phenomenon were aimed; hence, a hybrid technique for inquiry that combines quantitative and qualitative tools was implied. First, students' performance was assessed quantitatively by comparing grade differences between online and face-to-face instruction. Second, students' satisfaction with the university distance education portal during COVID-19 lockdown was assessed quantitatively using an online survey. Third, professors' experience with the online distant teaching was assessed qualitatively by series of online interviews. 
3.1. First: Course Grade Comparison. The course grades were used in this research as the primary comparative factor in assessing students' performance differences between online and face-to-face instruction. Grade comparison in four quizzes, mid-term exam, and final exam is made. Student level, gender, credit hours, and CGPA are considered as independent variables. As these academic and demographic variables have been suggested to affect academic performance [11], they were considered in the current research to decrease the possibility that any variation in student performance could be confounded by these demographic or academic variables, and not because the course was being taught in an online vs. face-to-face format.

Comparison of grades was made between two instruction modes of the same course, Introduction to Programming (MIS202), taught for the second year business students at a private university in Egypt: face-to-face mode in Spring 2019 (February-June 2019) versus online mode in Spring 2020 (February-June 2020) during the COVID-19 pandemic. Taught with the same course specifications and intended learning outcomes, the courses given in 2019 and in 2020 are having the same curriculum, materials, test bank, number of quizzes and assignments, student assessment methods and schedule, and weighting of assessment. Blueprints were compared between the final exam of Spring 2019 and that of Spring 2020, and they were found matching in terms of number of questions, question types, question marks, percentage of question marks to marks of exam, course ILOs covered by the questions, and question level of difficulties. The course was given by the same four professors in both compared semesters.

3.1.1. Grade Comparison Sample. The study consisted of 748 business students in the Faculty of Business Administration, Future University in Egypt. The face-to-face sample consists of 376 students, and those were all the students who completed the Introduction to Programming course (MIS2020) by faceto-face instruction mode in Spring 2019, while the online sample consists of 372 students, and those were the students who completed the same course but online in Spring 2020. As mentioned above, gender, GPA, credit hours completed by students, and students' age are considered independent variables in the study. Of the 748 total students, $43 \%$ were female, while $57 \%$ were male. Female percentage was approximately similar in both samples ( $44 \%$ female for the face-to-face sample and $39 \%$ female for the online sample). GPA was 3.15 on average for the overall participants and was almost similar for both samples (3.41 and 3.02 GPA for the face-to-face and online sample, respectively). All participants were year two students, who on average completed around 42 and 45 credit hours for the face-to-face and online sample, respectively. Participants' ages were almost equal in both samples, as illustrated in Table 1, demonstrating the sample demographic and independent variables separated by instruction modes.

3.1.2. Course Instruction. The MIS202 course was taught by four information systems professors at Future University in Egypt (FUE). The four professors had over 10-year teaching
TABLE 1: Sample demographic and independent variables separated by instruction modes.

\begin{tabular}{lccc}
\hline Variable & \multicolumn{3}{c}{ Mean } \\
& Face-to-face & Online & All \\
\hline Student enrolment & 376 & 372 & 748 \\
Gender (female) & 0.44 & 0.39 & 0.43 \\
GPA & 3.41 & 3.02 & 3.15 \\
Credit hours & 42.54 & 45.11 & 44.25 \\
Age & 19.48 & 20.00 & 19.98 \\
\hline
\end{tabular}

experience, and they have been teaching the course together since 2015. Based on students' formal evaluation, collected by FUE at the end of each semester, the four professors were considered outstanding instructors with excellent communication and teaching skills. In face-to-face and online course, the same materials, reference book, power point presentations, and class exercises were taught. Assignments and homework were similar and have the same level of difficulty.

In Spring 2019, the face-to-face class met twice weekly in an on-campus classroom, each class lasted 2 hours, and the course materials were uploaded on Moodle, the FUE official e-learning portal. Each professor has an office hour weekly in the on-campus office. Moodle is still used at FUE as the formal communication channel between students and professors and among students taking the same course. Course announcements and assignments are also posted on Moodle. In Spring 2020, during the COVID-19 lockdown, classes were conducted and recorded via online sessions using Zoom, each session lasted 2 hours, and the links to session recordings were posted on Moodle. Course materials, announcements, and assignments were uploaded on Moodle. A licensed Zoom account was given for each FUE student, and the capacity of the university's bandwidth and data center was enhanced to accommodate the online classes and the session recording and backups. During the COVID-19 lockdown, office hours were done on Moodle, and each professor was available online on Moodle during the office hour. Chat rooms and synchronous and asynchronous discussion forums were conducted. The information technology (IT) team of the university provided 24/7 online support for students on Moodle, where students can seek help by clicking an icon to receive help instantly.

3.1.3. Course Assessment. In this study, student performance was operationalized by course grades. Course grade calculation was identical in face-to-face and online modes. Course total grade is out of 100 and represents the sum of the students' marks in the final exam (40 grades) plus the course work (60 grades). The course work is the sum of three quizzes (each quiz is marked out of 10; in the face-to-face and online course, four quizzes were conducted and the best three grades were taken) plus three assessments (each assessment is marked out of 10). Quizzes and exams were designed by the four course instructors, using the same test bank, and this was typically applied in both face-to-face and online cases. 
In face-to-face mode of instruction, quizzes and final exam were conducted in paper format on-campus, while in online mode of instruction, quizzes and final exam were conducted online on Moodle. Online proctoring, as well as technical support, was available during quizzes and exams; in addition, students can post an online petition with screenshots in case of facing any technical problem that would prevent quiz/exam completion. After checking with the IT team, professors had the right to accept the petition and conduct a make-up quiz/exam for students.

3.1.4. Data Collection Procedures. The grades of the two groups of learners (376 face-to-face learners and 372 online learners) were collected over the past year and a half (February 2019-June 2020) by the author of this paper, a full-time professor at the Future University in Egypt (FUE), who participated in teaching the MIS202 course for FUE students in Spring 2019 and Spring 2020. Permission was taken from the university to anonymously analyze the data and publish the results for academic purposes.

A student satisfaction survey was posted in June 2020 on the university portal to collect students' feedback. Students taking all courses, not only the course considered in this research, were encouraged to fill the online survey. Additionally, in July 2020, the author of this paper conducted a series of semistructured interviews with a small sample of professors who taught online courses for the FUE students during the lockdown. Both the students' survey and the professors' interviews aimed to collect general data about the online learning experience during the COVID-19 lockdown.

3.1.5. Grade Comparison Results. The investigated research question of this study is whether there was a difference in student performance between face-to-face and online learners for the same course taught in two consequent semesters at the same university. To investigate this research question, first, a $t$-test was conducted with the calculation of mean, standard deviation, and difference. Table 2 compares the mean and standard deviation of the course grades separated by instruction modes. No significant difference was found in either the total grade or quizzes, course work, and final exam grades. The mean of course grades for both instruction modes was found similar; in addition, both groups had fairly similar standard deviations.

Second, a Chi-square method was used to compare grade distribution for both groups ( $\chi^{2}$ ranged from 0.60 to 2.3 with $\mathrm{df}=1$ and $p>0.05$ ). Chi-square is particularly useful for this type of comparison, checking if there is a statistically significant difference in grade distribution between the two groups of learners. It is worth mentioning that marks of 90 , $85,80,75,70,65,60,55,53$, and 50 refer to the grades of $A$, A-, B+, B, B-, C+, C, C-, D+, and D, respectively. A mark below 50 is a fail, and according to the university regulations, a student can withdraw a course after checking his/her course work, usually announced two weeks before the final exam.

Table 3 lists grade distribution for both face-to-face and online, separated by success/ fail and marks. It can be observed that the online learners had a slightly higher percentage of A's and B's as compared to the face-to-face students. On the other hand, face-to-face learners had a slightly higher percentage of C's and D's, with a considerably higher success rate. However, no significant difference was found when comparing grades of both groups with a critical value of 7.7 and a degree of freedom of 4 . Hence, no statistically significant difference was found between the two groups in terms of grade distribution.

It appears from Table 3 that students with higher GPAs perform better in online courses, whereas students with poor GPAs perform worse when taking courses in an online format compared to a face-to-face mode. This result was expected due to the fact that the distance learning during the COVID-19 lockdown deprived students with low GPA of the benefit of support and mentoring mechanisms provided by the university on-campus. A two-way ANOVA test was used to assess the differences between the multiple GPA means, and no significant difference was found in performance between online and F2F students with respect to GPA. Additionally, Chisquare test was also conducted to determine if there were differences in online and face-to-face learners' performance with respect to gender. The Chi-square test had alpha equal to 0.05 as criterion for significance. Hence, no statistically significant difference was found as an effect of the four independent variables on students' performance in the two groups of learners.

3.2. Second: Professors' Interviews. Interviews were conducted with a small sample of 8 full-time professors from different specializations at Future University in Egypt (FUE). Participants were interviewed about their general experience with the online distant teaching during the COVID-19 lockdown, expressing their interest, challenges, and drive to conduct this mode of teaching.

3.2.1. Interview Sample. All interviewees had over 10-year teaching experience, and they have been teaching different business courses at the university for at least 5 years. The sample was evenly balanced for gender, and all participants were familiar with the university e-learning tool, Moodle, but none of them had a previous experience with teaching classes on Zoom. Interviewees were selected based on convenience sampling; half of the interviewees were from the Information Systems Department, having a strong information technology (IT) background, while the other half were from the Accounting Department with fair IT skills.

3.2.2. Interview Procedures. Interviews were conducted online through Zoom sessions. Each interview session was 20-30 minutes long, and data collection was completed by saturation; this is when a feeling of closure is obtained with repeated answers. The interviews began with broad questions aiming to find out the professors' general evaluation of the online teaching, what motivated them to use the online tools, and what problems, if any, they experienced while 
TABLE 2: Comparison of course grades.

\begin{tabular}{|c|c|c|c|c|c|c|c|c|c|}
\hline \multirow{2}{*}{ Assessment items } & \multicolumn{3}{|c|}{ Face-to-face } & \multicolumn{3}{|c|}{ Online } & \multirow{2}{*}{$\begin{array}{c}\text { Difference } \\
\text { Mean }\end{array}$} & \multirow{2}{*}{$\begin{array}{l}t \text {-Test } \\
\text { Value }\end{array}$} & \multirow{2}{*}{$p$ level } \\
\hline & Mean & Std. dev & $\mathrm{N}$ & Mean & Std. dev & $\mathrm{N}$ & & & \\
\hline Quizzes & 26.122 & 4.812 & 376 & 25.120 & 5.271 & 372 & 1.002 & 1.445 & 0.000 \\
\hline Course work & 25.675 & 4.348 & 376 & 25.001 & 4.746 & 372 & 0.554 & 1.161 & 0.000 \\
\hline Final exam & 26.006 & 12.143 & 376 & 25.123 & 12.654 & 372 & 0.661 & 0.260 & 0.000 \\
\hline Total grade & 87.815 & 17.352 & 376 & 85.374 & 19.341 & 372 & 2.331 & 0.74 & 0.000 \\
\hline
\end{tabular}

TABle 3: Semester total grade distribution.

\begin{tabular}{|c|c|c|c|c|c|c|c|c|c|c|c|c|}
\hline \multirow{2}{*}{ Grade } & \multicolumn{11}{|c|}{ Success (\%) } & \multirow{2}{*}{ Fail (\%) } \\
\hline & $\mathrm{A}$ & $A-$ & $\mathrm{B}+$ & B & $\mathrm{B}-$ & $\mathrm{C}+$ & $\mathrm{C}$ & $\mathrm{C}-$ & $\mathrm{D}+$ & $\mathrm{D}$ & Success & \\
\hline Face-to-face $(N=376)$ & 12.72 & 7.51 & 13.01 & 10.98 & 10.98 & 13.58 & 8.96 & 9.24 & 2.89 & 2.89 & 92.76 & 7.24 \\
\hline Online $(N=372)$ & 13.58 & 8.321 & 14.21 & 12.09 & 9.03 & 14.98 & 8.89 & 4.51 & 2.04 & 2.95 & 90 & 10 \\
\hline
\end{tabular}

using these tools. During the interview sessions, participants were asked to point out what they like/dislike in the online long distance teaching experience during the lockdown and suggest ways to improve it.

Sessions were recorded, transcribed, and manually coded through textual analysis. Following a systematic deductive approach of qualitative data analysis [19], the transcript of the collected data was reviewed to identify repeating patterns. Each pattern was then given a code. Relevant codes were combined into overarching themes, where themes are integrated to convey the story of the data in a logical manner.

\subsubsection{Interview Results}

Advantages of the Online Teaching during the COVID-19 Lockdown. All interviewees agreed that conducting quizzes and exams online is much easier in terms of correction and grade calculation as this was done automatically via the portal, while this was done manually in class, adding to professors' workload. According to professors this will encourage them to increase the amount of assignments and pop-up quizzes for more practice in the future online teaching modes.

All interviewed professors agreed that sharing the link of the recorded online lectures provided students with the ability to replay videos, revise materials, and skip unneeded parts of the lecture. However, this same option caused a "great decrease in students attendance in online classes, preventing students from class participation" as stated by the interviewed professors. It is worth mentioning that, based on the university statistics, less than $50 \%$ of enrolled students were regularly attending online classes, while more than $96 \%$ played the recorded classes offline at their own pace. The majority of interviewees reported that, unexpectedly, the communication between faculty and students during the COVID-19 lockdown increased using new means of online IT-based tools; "there has been a greater than ever communication between professors and students using online chat, forums and regular webinars" as expressed by an accounting professor.
A professor with IT background believed that "online education will be further accelerated and it will eventually become an integral component of higher education"; she also believed that the COVID-19 lockdown was "a good opportunity for the university to upgrade its e-learning infrastructure; this includes enhancing Internet bandwidth, enlarging the capacity of data centers, purchasing licensed e-learning tools, and improving students and professors IT skills." Most professors also praised the use of enterprise social network tools during the COVID-19 lockdown to manage meetings between faculty members; "this provided more participation in decision-making, transparency, speed of decisions and implementation" as cited by an IT professor.

Disadvantages of the Online Teaching during the COVID-19 Lockdown. For half of the interviewed professors, the Internet connection quality and reliability represented a major obstacle for teachers and students in some online lectures and during some online exams. The majority of respondents commented that, in online learning, students were deprived of the one-on-one and face-to-face assistance provided by the teaching assistant in labs/classrooms; in addition, students with low CGPA were deprived of some support mechanisms provided to them on-campus such as the support of the Mentoring Unit for students with learning difficulties. All interviewees agreed that one of the main disadvantages of the lockdown is the cancellation of students' on-campus activities and the cancellation of the students' summer training and internships. One professor complained that "teaching and working from home increased working hours and interfered with the family life."

3.3. Students' Satisfaction Survey. An online survey was posted by the university on the student portal. The survey aimed to assess students' satisfaction with the university distance education portal used during COVID-19 lockdown. The survey included 20 questions: the majority of questions were related to the infrastructure with the goal of understanding students' satisfaction with the access, easiness/ 
difficultness, and perceived value of the portal; another group of questions were related to the available learning material and its content; finally, the other group of questions assessed students' satisfaction with the technical support service provided by the university.

3.3.1. Survey Sample. The electronic students' satisfaction survey was posted on the university portal in July 2020 . Students were encouraged to fill the survey online before being able to access their spring semester results from the portal. Students were informed that the survey is anonymous and that the main objective is to enhance the online learning experience via the university portal. A total of 435 students responded anonymously to the survey, with a response rate of $25 \%$. Senior students were more proactive in responding to the survey (level 4 and level 3 students represented $37.7 \%$ and $27.6 \%$, respectively), while first year students were less represented in the survey (level 1 and level 2 students represented 17.2\% and $17.5 \%$, respectively, of the total survey participants). Female students represented $59 \%$ of the total respondents. As the Accounting Department is the biggest in terms of students' number, followed by Marketing and Finance Departments, survey respondents from Accounting Department represented 44.8\%, Marketing $20 \%$, Finance 18.2, Human Resources $9.4 \%$, and finally Management Information Systems 7.6\%.

3.3.2. Survey Results. In general, most of the students are satisfied with the simplicity of the portal and accessibility of materials. A moderate majority (74\%) of the students who filled the survey agreed that the university distance education portal employed during COVID-19 lockdown is easy to use. A smaller percentage (62\%) agreed that it is easy for students to enter the portal at all times. A high majority (89\%) agreed that one of the advantages of the university portal is that there are multiple ways to access it from a mobile phone, computer, or laptop. Students were unsatisfied with the university technical support team, as only $32 \%$ agreed that it is easy to reach the IT team to solve their problems with the portal. On the other hand, the highest majority of students (89\%) agreed that materials are available on the portal adequately and that lectures are presented in an organized and understandable manner. Although the majority of students (75\%) are satisfied with the diversity of presentation of lectures on the portal (videos, PowerPoint presentations, online sessions), only half $(50 \%)$ agreed that learning methods through the online portal ensure student-to-student and student-toinstructor interaction. Furthermore, only $45 \%$ of students appraised the electronic mechanism used to receive student petitions during exams and provide support to students, and only $43 \%$ agreed that the university takes measures to correct any unfair practice as soon as it is discovered. An even smaller percentage (42\%) agreed that distance education portal is useful in the overall learning experience.

\section{Results and Discussion}

This study is looking at the effect of the sudden shift from face-to-face to online distance learning due to COVID-19 lockdown at one of the universities in Egypt. For a total of 376 business students, the study investigated the difference in academic performance, in terms of course grades, between face-to-face learners taught on-campus in Spring 2019 and learners who completed the same course by the same professors but fully online via long distance learning during the COVID-19 lockdown in Spring 2020 semester. Course grades were used as the primary comparative factor. Additionally, student satisfaction online survey and e-interviews with a small sample of professors were conducted to collect general data about the online learning experience during the COVID-19 lockdown.

Based on the $t$-test conducted to compare grades of quizzes, course work, and final exam for the two groups and the Chi-square test carried out to compare grade distribution for both groups, there was no significant difference in students' grades between face-to-face and online teaching modes of the same course taught during COVID-19 lockdown semester and the semester before. No significant effect of demographic and academic variables was detected on students' performance in the two groups of learners. This result confirms many previous studies, conducted in 2019 before pandemic, suggesting no differences in students' performance between online and face-to-face courses $[8-10,20]$. While it was expected that the unplanned and rapid move to online distance learning at the time of pandemic would result in a poor learning experience [14], the current research suggests that, despite shortage of infrastructure and lack of practice in online education, students' performance in terms of grades was not affected.

From course grades, it appeared that students with higher GPAs perform better in online courses and students with poor GPAs perform worse. Although this result was not found significant, it is obvious that since COVID-19 lockdown students were deprived of a lot of on-campus support. Mostly, students with low GPA were deprived of one-to-one personal support and advise offered by senior students, teaching assistants, and mentoring staff. According to Joosten and Cusatis [21], students who require more assistance or are struggling academically expect greater communication and interactivity from their instructor. The greater their perception of instructor interactivity, the greater their perception of learning. Adding an e-mentoring feature to university portal can support students in area of weakness by providing extra resources, answering students' queries, and/or setting online one-to-one meetings with mentoring staff.

Aiming to comprehend the overall learning and teaching experience during the lockdown, an online students' satisfaction survey and interview Zoom sessions with professors were conducted in July 2020 . The statistical analysis of the survey and the textual analysis of the interviews reveal a common positive attitude among learners and educators towards the shift to online distance learning. Contrary to what was expected $[13,22]$, that this sudden shift would be 
associated with high level of anxiety, the current study supports a similar empirical study [14], implying that both learners and educators adapted fast and had positive attitude towards the change during the pandemic.

While most of the students praised the ease of use of the online portal, it was also reported that the current portal was not useful in the overall learning experience. This might be due to bad Internet connectivity at some students' homes, which occasionally prevented them from accessing the portal. Similarly, some professors stated that the Internet connection quality and reliability represented a major obstacle to online teaching. The shift to online learning has highlighted the digital inequality between those who have access to reliable Internet infrastructure, laptops, and smartphones and those that do not [13]. In particular, in developing countries such as Egypt, there are variations in Internet speed and reliability based on neighbourhood and household income.

In their responses to the survey and interviews, both students and professors highlighted the issue that students were deprived of some support mechanisms provided to them on-campus such as the support of the Mentoring Unit to students with learning difficulties. This result confirms another study [23] reporting that COVID-19 has higher negative impact on learners who have already been experiencing learning difficulties. These learners can no longer benefit from supporting services provided to them only faceto-face.

While all professors favored online exams as they are easier to mark, the majority of students, on the other hand, complained about the lack of measures to correct any unfair practices and the weak mechanism for receiving student petitions during online exams. This result would suggest an adjustment in alternative assessment and evaluation methods, where formative assessment is crucial. As prior to pandemic, formative assessment involved only classroom observation and homework, this needs to be done now at a distance through both synchronous and asynchronous means [24]. Based on the results of the current study, discussed above, key recommendations can be suggested as follows.

\section{Recommendations}

5.1. Recommendations for Higher Education Institutions. Support should be given to instructors to create interactive online materials. Universities need to enhance Internet bandwidth, enlarge the capacity of data centers, purchase licensed e-learning tools, and provide training for students and professors on needed IT skills. Online training and skills enhancement workshops should be emphasized to compensate for on-campus activities. Effective and responsive IT technical support and troubleshooting services should be provided to students, especially during quizzes and exams. Support can be offered 24/7 through phone calls, e-mail, online live chat, and video guides. Developing and maintaining robust communication channels between higher education management, students, and teaching staff are essential in keeping all stockholders informed and aware of next steps. Multiple informational and introductory online sessions should be maintained. Developing and maintaining robust communication strategies with staff, faculty, and students are essential in keeping all entities informed and apprised of the next steps in the transition, training, and ongoing support. Institutions of higher education may make the gradual shift away from traditional instruction; they may implement online long distance teaching to capture a larger worldwide audience. This result is especially important for some developing countries, like Egypt, that decided to integrate face-to-face with online distant learning in all future higher education plans, to cut cost, reduce student density, and make a gradual transformation of students to lifelong learners.

5.2. Recommendations for Instructors. A strong effort should be made to design online courses rather than moving faceto-face materials of a course into the online environment. Interactivity and feedback should be emphasized during the online classes to increase students' attendance, where virtual chat rooms and forums for students-to-students and students-to-instructor online interaction should be designed. There should be clear instructions concerning exams, quizzes, and assignments to inform learners of how to get help and how to place petitions.

\subsection{Recommendations for the Higher Education Portal} Designers. It is recommended that learning management portals incorporate higher interactivity level with instructor and peers. Synchronous and asynchronous forms, blogs, message boards, and chat rooms are all possible tools to reach the needed interactivity levels to enhance retention rate of students, support students in need, and replace individual face-to-face support and mentoring provided in conventional learning on-campus. University portals need to get more benefit from the integrative nature of the web, by integrating course materials with relevant academic and professional resources available online, where students can extend their learning experience.

Students praised the mobility of the portal, being able to access materials with different devices and from different places. The mobility feature of the university portal should be further emphasized; designers need to ensure mobile access to materials with various Internet connectivity conditions, providing the option to complement or even replace videos with text and allowing users to pick the content media suiting available device, smart phone, and connectivity, hence increasing the portal mobility. E-mentoring feature can compensate for on-campus support mechanism and would mentor students in any area of weakness by providing extra resources.

\section{Conclusion, Limitations, and Future Work}

The aim of this research was to examine the effect of the sudden shift from face-to-face to online distance learning due to COVID-19 lockdown at one of the universities in Egypt. Course grade comparison and students' and professors' 
feedback were considered to investigate the overall learning experience. The results suggested that this unplanned and rapid shift at the time of pandemic did not result in a poor learning experience as was expected. However, the findings provided specific recommendations for future application of online distance learning. Enhancing the technological infrastructure, providing responsive troubleshooting services, and establishing robust communication channels between management, learners, and professors all are crucial factors for higher education institutions to consider. University portal designers need to think carefully about how to ensure high interactivity between learners and professors and among peers. In addition, the mobility feature of the university portal should be further emphasized.

Although it is too early to judge how reactions to COVID-19 will affect education systems around the world, there are signs suggesting that it could have a lasting impact on the trajectory of learning innovation and digitization. The results of this study provide specific recommendations and best practice for future application of online distance learning. Since Egypt decided to integrate online distant learning into all future higher education plans, the results of this research would be especially vital for universities in Egypt and other developing countries.

Although the study suggests no significant effect of some learners' demographic and academic variation (gender, age, GPA, and credit hours) on the results, the sample could still be a limitation. The sample used was from just one institution and only included one course that was taught in both formats for year two students of a business faculty in Egypt. Future studies should consider a comparison of student performance over a longer period, not only between two consecutive semesters, as this would ensure more reliable results. Future studies should also incorporate additional academic and demographic variables as well as other course types like laboratory-based courses to expand the scope of the results. Future research can also incorporate other universities in the region and worldwide to assess regional differences and possible cultural dimensions. While this study considered course grades as the primary comparative factor, this may be limited in scope and depth; future studies should consider students participation, retention, and attendance as part of the overall learning experience to provide specific short and long term implications of the online learning mode.

\section{Data Availability}

The data used to support the findings of this study are available from the author upon request.

\section{Conflicts of Interest}

The author declares no conflicts of interest.

\section{References}

[1] World Economic Forum, "3 ways the coronavirus pandemic could reshape education,” 2020, https://www.weforum.org/ agenda/2020/03/3-ways-coronavirus-is-reshaping-educationand-what-changes-might-be-here-to-stay.
[2] DAAD, "COVID-19 impact on international higher education: studies \& forecasts," 2020, https://www.daad.de/en/ information-services-for-higher-education-institutions/ centre-of-competence/COVID-19-impact-on-internationalhigher-education-studies-and-forecasts/\#Global\%20and\% 20 cross-national\%20analyses.

[3] C. Hodges, S. Moore, B. Lockee, T. Trust, and A. Bond, "The difference between emergency remote teaching and online learning," 2020, https://er.educause.edu/articles/2020/3/thedifference-between-emergency-remote-teaching-and-onlinelearning.

[4] DAAD, "Targeted support for universities in crisis management," 2020, https://www2.daad.de/der-daad/daad-aktuell/en/ 77069-targeted-support-for-universities-in-crisis-management/.

[5] StudyPortals, "International student plans-impact of COVID-19,” 2020, https://studyportals.com/intelligence/ international-student-plans-impact-of-COVID-19/.

[6] UNESCO, "Education: from disruption to recovery: COVID19 impact on education," 2020, https://en.unesco.org/ COVID19/educationresponse.

[7] A. T. Komani and G. M. Chisomo, "Expanding access to higher education in public universities through open and distance learning (ODL) in Malawi: quality issues," International Journal of Engineering Science and Management (IJESM), vol. 1, no. 3, pp. 88-96, 2019.

[8] T. Soesmanto and S. Bonner, "Dual mode delivery in an introductory statistics course: design and evaluation," Journal of Statistics Education, vol. 27, no. 2, p. 90, 2019.

[9] J Tan, "factors on the effectiveness of delivering business technology courses: on-ground versus online," International Journal of Accounting and Financial Reporting, vol. 9, no. 4, pp. 19-40.

[10] R. Lorenzo-Alvarez, T. Rudolphi-Solero, M. J. Ruiz-Gomez, and F. Sendra-Portero, "Medical student education for abdominal radiographs in a $3 \mathrm{D}$ virtual classroom versus traditional classroom: a randomized controlled trial," American Journal of Roentgenology, vol. 213, no. 3, pp. 644-650, 2019.

[11] J. Cavanaugh and S. J. Jacquemin, "A large sample comparison of grade based student learning outcomes in online vs. face-to-face courses," Online Learning, vol. 19, no. 2, 2015.

[12] P. Nyer, "The relative effectiveness of online lecture methods on student test scores in a business course," Open Journal of Business and Management, vol. 07, no. 04, pp. 1648-1656, 2019.

[13] A. Bozkurt, I. Jung, J. Xiao et al., "A global outlook to the interruption of education due to COVID-19 pandemic: navigating in a time of uncertainty and crisis," Asian Journal of Distance Education, vol. 15, no. 1, pp. 1-126, 2020.

[14] R. Hjelsvold, A. Bahmani, and M. Lorås, "First impressions from educators as NTNU transitions to an online only mode of learning," 2020, https://www.researchgate.net/publication/ 341042510 .

[15] WENR, World Education News, "Education in Egypt. Education system profiles," 2020, https://wenr.wes.org/2019/02/ education-in-egypt- 2 .

[16] Almalnews, The Future of Distance Learning in Higher Education after COVID-19, The Egyptian Ministry of Higher Education, Cairo, Egypt, 2020, https://almalnews.

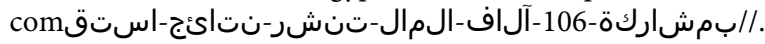

[17] A. Shahzad, R. Hassan, A. Y. Aremu, A. Hussain, and R. N. Lodhi, "Effects of COVID-19 in E-learning on higher education institution students: the group comparison between male and female," Quality \& Quantity, 2020. 
[18] A..,V. Alvarez, "The phenomenon of learning at a distance through emergency remote teaching amidst the pandemic crisis," Asian Journal of Distance Education, vol. 15, no. 1, 2020.

[19] H. R. Bernard and G. W. Ryan, Analyzing Qualitative Data: Systematic Approaches, Sage Publications, Inc, 2010.

[20] J. Paul and F. Jefferson, "A comparative analysis of student performance in an online vs. face-to-face environmental science course from 2009 to 2016," Frontiers in Computer Science, vol. 1, no. 7, 2019.

[21] T. Joosten and R. Cusatis, "A cross-institutional study of instructional characteristics and student outcomes: are quality indicators of online courses able to predict student success?" Online Learning, vol. 23, no. 4, pp. 354-378, 2019.

[22] S. Sundarasen, K. Chinna, K. Kamaludin et al., "Psychological impact of COVID-19 and lockdown among university students in Malaysia: implications and policy recommendations," International Journal of Environmental Research and Public Health, vol. 17, no. 17, p. 6206, 2020.

[23] B. Haßler, "Continue or reboot? Overarching options for education responses to COVID-19 in low- and middle-income countries," Zenodo, 2020.

[24] J. Liberman, V. Levin, and D. Luna-Bazaldua, Are Students Still Learning during COVID19? Formative Assessment Can Provide the Answer, World Bank Blogs, Washington, DC, USA, 2020, https:// blogs.worldbank.org/education/are-students-still-learning-duringcovid-19-formativeassessment-can-provide-answer. 